\title{
Do Happy People Make Optimistic Investors?
}

\author{
Guy Kaplanski, Haim Levy, Chris Veld, and Yulia Veld-Merkoulova*
}

This version: February 132013

\begin{abstract}
*Guy Kaplanski is from Bar-Ilan University, Ramat Gan, 52900, Israel, e-mail: guykap@ biu.ac.il; Haim Levy is from the Hebrew University of Jerusalem, Jerusalem, 90905, Israel, e-mail: mshlevy@ mscc.huji.ac.il; Chris Veld is from the University of Glasgow, Glasgow, G12 8QQ, United Kingdom, e-mail: chris.veld@ glasgow.ac.uk; Yulia Veld-Merkoulova is from the University of Glasgow, Glasgow, G12 8QQ, United Kingdom, e-mail: yulia.veldmerkoulova@glasgow.ac.uk. The LISS panel data were collected by CentERdata (Tilburg University, The Netherlands) through its MESS project funded by the Netherlands Organization for Scientific Research (NWO). This paper benefits from the helpful comments of Jo Danbolt, Marcel Das, Ming Dong, Chris Florackis, Richard Harris, Alexandros Kostakis, Luis Muga, Antonios Siganos, George Skiadopoulos, Patrick Verwijmeren, and participants at the Conference of the European Financial Management Association in Barcelona (June 2012), the MESS workshop in Amsterdam (August 2012), the Northern Finance Conference in Niagara Falls (September 2012) and seminars at the University of Exeter, University of Glasgow, University of Liverpool, and University of Piraeus. Special thanks go to an anonymous referee and to Stephen Brown (the editor) for helpful comments. Finally, the authors thank Marije Oudejans for her help with the panel data and Micaela Maftei for editorial assistance. The authors gratefully acknowledge additional financial support from La Chaire Dauphine-ENSEA — Groupama "Les Particulier face au risque" of the "Fondation du Risque" and L'Agence Nationale de la Recherche in the context of the project ANR Risk. Chris Veld also acknowledges financial support from the Carnegie Trust for Universities of Scotland. Haim Levy acknowledges financial support from the Krueger Center of Finance.
\end{abstract}




\title{
Do Happy People Make Optimistic Investors?
}

\begin{abstract}
Do happy people predict future risk and return differently from unhappy people, or do individuals rely only on economic facts? We survey investors on their subjective sentimentcreating factors, return and risk expectations, and investment plans. We find that non-economic factors systematically affect return and risk expectations, where the return effect is more profound. Investment plans are also affected by non-economic factors. Sports results and general feelings significantly affect predictions. Sufferers from seasonal affective disorder have lower return expectations in the autumn than in other seasons, supporting the Winter Blues hypothesis.
\end{abstract}

Keywords: sentiment-creating factors; sentiments; individual investors; mood; seasonal affective disorder.

JEL classification: G02, G10, G14. 


\section{Introduction}

Several market-based empirical studies show that non-economic factors (for example, aggregate investor sentiment) are significantly correlated with stock prices. Investor sentiment is defined in the literature in various ways. The most widely accepted definition is probably that suggested by Baker and Wurgler (2007). They define investor sentiment as "investors' belief about future cash flows and risk not justified by the facts at hand" (p. 129). We employ this definition in this study, and we analyze the direct link between sentiment and risk and return expectations on the individual level. While we do not employ an aggregate market sentiment empirical study, we use previously published sentiment results as a springboard for establishing some of the hypotheses tested in this paper on the individual investor level.

First, we explore the association between sentiment-creating factors reported by each individual and a "general feeling" (mood) variable. Second, we study the relation between sentiment-creating factors and the individual's subjective market judgment regarding expected return and volatility (risk). Finally, we explore whether and how sentiment affects actual investment plans. To the best of our knowledge, this is the first study to examine, on the individual level, the direct relation between sentiment-creating factors, subjective estimates of future return and risk, and investment plans, where the analysis uses data from a sample of subjects who actually trade in the stock market. Working with data on individual investors who completed a questionnaire in different months, different days, and different hours of the day, the likelihood that some other common factors induce the observed correlation is relatively small; hence, we show compelling evidence of a causal relation between sentiment and individuals' return expectations. 
The cross-sectional analysis relies on the Longitudinal Internet Studies for the Social Sciences (LISS) panel of CentER data at Tilburg University. ${ }^{1}$ This panel consists of a sample of approximately 5,000 households representative of the population of the Netherlands. After screening those individuals who hold stocks in their investment portfolios, we submitted questionnaires to approximately 900 individuals in three waves during a time span of one year. Each individual reported next-month and next-year subjective return and risk expectations regarding both the Dutch and U.S. stock markets. Each individual also reported on several sentiment-creating factors, some of which are found in previous studies to be correlated with stock prices at the aggregate level. These factors include general feeling (which has not been tested before and allows us to test for the individual mood), recent results for the individual's favorite sports team, the individual's perception of contemporaneous weather, and whether the individual is "a spring person" in general and suffers from seasonal affective disorder (SAD) in particular.

Since the questionnaire was filled out three times during the year, we can test what effect the season, particularly the SAD season, has on sentiment. As the subjects filled out the questionnaire on different days, the reported day can be used to test for the day-of-the-week sentiment effect. Unlike market-based empirical studies, we also have data corresponding to weekend non-trading days, which are generally characterized by above-average positive mood. Finally, each individual reported on plans to buy or sell stocks in the coming month. Thus, each individual simultaneously reports on subjective stock market return and risk expectations, subjective perception of contemporaneous sentiment-creating factors, and investment plans.

\footnotetext{
${ }^{1}$ For studies that rely on similar internet panel data that are representative of the population of The Netherlands see, for example, Veld and Veld-Merkoulova (2008), Guiso, Sapienza, and Zingales (2008), Bellemaere, Kröger, and Van Soest (2008), Von Gaudecker, Van Soest, and Wengström (2011), and Van Rooij, Lusardi, and Alessie (2011).
} 
Our statistical analysis reveals a strong and significant association between several sentiment-creating factors, individual mood (as measured by the general feeling variable) and individual expectations regarding future stock market returns. On average, more positive sentiment is accompanied by higher return expectations and higher intention to buy (rather than sell) stocks. The surprising result of this study is not the direction of the sentiment effect but its magnitude and consistency: comparing the cumulative distributions of return expectations among all individuals, we find a first-degree stochastic dominance (FSD), where the subjective return expectations of the subjects who score highly on the non-economic sentiments are systematically higher than those of subjects experiencing lower sentiments; namely, the two cumulative distributions do not intersect.

Several other interesting results emerge from our analysis. First, sentiment affects expected returns more intensely than expected risk. We find that, although more positive sentiment tends to be accompanied by lower volatility expectations, this result is significant only in one case out of four. Second, we find that individual investors are generally consistent in their short-term and long-term expectations, recent trading activity, and future investment plans. Finally, consistent with psychological evidence, general mood on the weekends is relatively high. However, we do not find that the relatively high mood on weekends is accompanied by high return expectations.

The remainder of this paper is organized as follows. Section II presents the data and the sample. Section III presents the sentiment-creating variables and the hypotheses tested, while reviewing the relevant literature. The empirical results are reported in Section IV. Finally, Section V sets forth our conclusions. 


\section{Data and sample}

The LISS panel is a representative sample of individuals living in the Netherlands. ${ }^{2}$ In order to focus on individuals who actually invest in stocks, in a preliminary step, which took place in October 2010, 7,428 members of the panel $^{3}$ were asked whether they held equities in their investment portfolios. The 929 subjects who reported that they held equities in their portfolios were later approached in three waves, in November 2010, February 2011, and June 2011. Panel A in Table 1 reports the sample size and the number of subjects who completed the questionnaire in each wave. Overall, 577 individuals submitted at least one complete questionnaire (389 submitted three complete questionnaires), yielding a total of 1,465 complete questionnaires. We also have access to the demographic characteristics of the participants, collected from the LISS panel.

\section{[Please insert Table 1 here]}

Panels B and C report demographic and financial characteristics of the 577 subjects. By construction, the studied subsample represents the population that actually trades in the stock market. It is biased toward older, wealthier, educated married male individuals. ${ }^{4}$

To examine the sentiment hypothesis on the individual level, the subjects were asked three sets of questions. In sets one and two, the subjects reported their subjective expectations and past and future investment plans, respectively. These questions explore whether the sentiment characterizing individuals' beliefs affects their investment plans. Panel A in Table 2 reports descriptive statistics corresponding to these sets of questions. The subjects reported their

\footnotetext{
${ }^{2}$ Detailed information about the LISS panel can be found at: www.lissdata.nl and in Scherpenzeel and Das (2010).

${ }^{3}$ These 7,428 members belong to approximately 5,000 households. This result means that some households have more than one member in the panel.

${ }^{4}$ For example, $65 \%$ of the subjects are males, the average age is 56 years old, $88 \%$ are homeowners, and $53 \%$ hold a college or university degree. These numbers are in line with those of a survey study of Graham, Harvey, and Huang (2009), who use data from the UBS/Gallop investor survey from 1996 to 2002 . The investors in their sample are, on average, 49 years old; $60 \%$ of them are college graduates, and $26 \%$ have postgraduate education.
} 
subjective expectations corresponding to both future return and future risk (volatility). Subjects report their short-term, next-month expectations and their longer-term, next-year expectations regarding both the Amsterdam Exchange Index (AEX) index, which consists of 25 stocks representative of Euronext Amsterdam, and the U.S. S\&P 500 Index. The last two columns report descriptive statistics corresponding to the second set of questions regarding the individual's past and planned investments. Trading activities are diversified across choices. However, in any given month the majority of individuals did not trade at all.

[Please insert Table 2 here]

In the third set of questions, subjects reported several sentiment-creating factors and their general tendency toward optimism or pessimism. These questions explore whether individual beliefs about future returns and risk are associated with their mood and feelings as derived from the various sentiment-creating factors, while controlling for their general tendency toward optimism or pessimism. Panel B reports descriptive statistics from this set of questions. Subjects reported on their contemporaneous general feeling, their subjective perception of the weather over the last two days, whether they generally suffer from SAD, their preferred season of the year, and their favorite sports team's performance. To avoid biases due arising from question format, the questions include a wide range of choices evenly distributed around a neutral choice. Finally, the day of the week was recorded on which the subjects filled out the questionnaire, which allows us to explore the possible presence of day-of-the-week effects.

\section{Hypotheses}

We employ five groups of variables to study what effect individual sentiment has on individual return and risk expectations. The first group of variables explores a general feeling 
sentiment effect. The next three groups explore the weather, SAD, and sports results sentiment effects, which have been found to be correlated with the stock market on the aggregate level. The final group contains data on day-of-the-week effects. In all cases, these variables' choices are ordered from bad mood to good mood. Thus, the higher the assigned choice by the individual, the better the reported mood. The hypotheses regarding these variable groups are presented below.

\section{A. General sentiment effect hypothesis}

Numerous psychological studies show that mood, typically defined as a coherent affective state that lasts for minutes or hours, can affect a person's decision-making process. In a recent review, Mitchell and Phillips (2007) conclude that even mild fluctuations in mood can have a significant influence on neural activation and cognition. Specifically, both positive and negative moods impair executive functions such as planning ability, verbal fluency, and creativity, where positive mood generally causes heuristic processing and negative mood promotes systematic thinking. ${ }^{5}$ These effects translate into mood-induced changes in expectations. Johnson and Tversky (1983) show that negative affect (or negative mood) induced in subjects leads them to make higher estimates of (non-financial) risks, while positive affect decreases perceived probability of risky events. Nygren, Isen, Taylor, and Dulin (1996) find that positive affect causes subjects to be more optimistic as they tend to overestimate probabilities of winning compared to probabilities of losing. We expect that the tendency of people in a better mood to overestimate the probabilities of winning and to underestimate overall risks will directly lead to greater expected stock market returns.

\footnotetext{
${ }^{5}$ Mood also affects other aspects of behavior, like investment decisions (Kaplanski and Levy, 2010a), social judgments and memory in general (e.g., Ashby, Isen, and Turken, 1999; Dreisbach and Goschke, 2004), and willingness to take risks in particular (Etzioni, 1988; Hanoch, 2002; Mehra and Sah, 2002).
} 
To assess the relation between individual mood and stock market expectations, we employ the "General-feeling" variable, which ranges from 1 (feels very bad) to 5 (feels great), and test the following hypothesis:

H1: The better the individual's general feeling, the higher the expected return.

\section{B. Weather sentiment effect hypothesis}

Saunders (1993) and Hirshleifer and Shumway (2003) find that sunshine is positively correlated with stock returns on the New York Stock Exchange (NYSE) and on other markets worldwide, respectively. Cao and Wei (2005) find a negative correlation between temperature and returns. Goetzmann and Zhu (2005) find that NYSE spreads widen on cloudy days. Thus, the empirical evidence suggests that weather and sentiment may be correlated. ${ }^{6}$

However, several difficulties arise in analyzing weather at the level of individuals. First, there are many weather factors (including temperature and sunshine, among others), that may affect a person's mood. Second, working with individual data, it is necessary to account for the fact that what one individual considers good weather, another individual may consider normal or bad weather. Third, different individuals are exposed to different weather depending on where they live. Taking into account these difficulties, a key feature of the weather tests in this study is that they do not rely on objective weather conditions but rather on individuals' own subjective perception of contemporaneous weather. Employing the "Perceived-weather" variable, which ranges from 1 (very bad weather) to 5 (very good weather), we test the following hypothesis:

H2: The better the individual's perceived weather, the higher the expected return.

\footnotetext{
${ }^{6}$ There is also some evidence to the contrary: Pardo and Valor (2003), for example, study the weather effect for the Spanish stock market and find that there is no influence of weather on stock prices.
} 


\section{SAD sentiment effect hypothesis}

Kamstra, Kramer, and Levi (2003) find that returns on the stock market are significantly correlated with the season of the year. They argue that SAD, which is responsible for seasonal fluctuations in mood in a large proportion of the population, ${ }^{7}$ affects individual willingness to take risk, hence affecting stock returns. Recently, Kramer and Weber (2012) directly linked SAD and seasonal fluctuations to a degree of financial risk aversion. ${ }^{8}$

$\mathrm{SAD}$ is a cyclic illness characterized by episodes of fall and winter depression (also known as "Winter Blues"), alternating with periods of normal mood or mild elation and behavioral activation during the spring and summer. According to Kamstra, Kramer, and Levi (2003), the effect of SAD on stock prices is asymmetric around the winter solstice: with the increased risk aversion due to SAD in the autumn, prices rise less quickly than they would otherwise. After the levels of risk aversion return to their "normal" levels at the end of winter, the recovery of prices from their initial (lower) levels increases returns.

Employing the $S A D$ variable, which is equal to 1 if the individual does not suffer from SAD and or 2, 3, or 4 if the individual suffers mildly, suffers, or strongly suffers from SAD, respectively, we test the following hypothesis:

H3: Stock market return expectations reported by SAD sufferers in the autumn are lower than their own expectations reported in the winter and in the spring or summer.

\footnotetext{
${ }^{7}$ According to Mersch, Middendorp, Bouhuys, Beersma, and Hoofdakker (1999), 3\% of the Dutch population suffer from severe SAD, and $8.5 \%$ suffer from mild SAD. These numbers are very similar to those obtained in our study (about $3 \%$ of the sample suffer from severe SAD and an additional $6 \%$ suffer from SAD).

${ }^{8}$ Other seasonal patterns that are consistent with the SAD explanation are found in data on government securities by Kamstra, Kramer, and Levi (2011), in analysts' stock earnings forecasts by Dolvin, Pyles, and Wu (2009) and Lo and $\mathrm{Wu}$ (2008), in initial public offerings by Dolvin and Pyles (2007), and in flows of capital in and out of safe and risky categories of mutual funds by Kamstra, Kramer, Levi, and Wermers (2011).
} 


\section{Sports sentiment effect hypothesis}

Investigating 39 stock markets worldwide, Edmans, García, and Norli (2007) find that following important international sports games, in particular soccer games, the losing country's stock market exhibits a significant negative effect, while that of the winning country exhibits a positive, though insignificant effect. Kaplanski and Levy (2010b) show that the FIFA World Cup creates a long-lasting negative effect that is exploitable. Ashton, Gerrard, and Hudson (2003) find a significant association between the performance of England's soccer team and the FTSE 100.

In this study, the subjects reported which sport they like, if any, and how their favorite team performed in the last three days. Employing the Sport-result variable, which ranges from 1 (bad result, from the individual's point of view, in an important game) to 5 (good result in an important game), we test the following hypothesis:

H4: The better the individual's favorite sports team's result, the higher the expected return.

E. Day-of-the-week sentiment effect hypothesis

According to empirical psychological evidence, the weekend is associated with higher average positive mood compared to weekdays. Egloff, Tausch, Kohlmann, and Krohne (1995), for example, find that "positive-affect-pleasantness" peaks on weekends and Helliwell and Wang (2011) find that people are significantly happier on weekends. Based on the psychological evidence, and employing "days of the week" dummies, we test the following hypothesis:

H5: Individual mood (general feeling) on weekdays is lower than on weekends, which, in turn, negatively affects return expectations. 
Regardless of whether H5 holds, in all tests in this study we control for day-of-the-week. One example is sufficient to demonstrate why this is important: most sport games are played over the weekend; hence, if there is a Monday effect in expectations, this may induce a spurious sports sentiment effect.

F. Overall sentiment effect and investment plans hypotheses

In all the above hypotheses, we examine the effect of each sentiment factor in a multiple regression. While it is possible that each sentiment factor has a relatively low impact, the overall sentiment effect of all factors taken together may be strong and substantial. Therefore, we also employ sentiment-creating factors to construct a single sentiment index: the Individual Sentiment Index (ISI), and use it to test the overall sentiment hypothesis, which makes no distinction between the exact sources of non-economic sentiment:

H6: The larger the ISI (that is sentiment is more positive), the higher (lower) the expected return (volatility).

Finally, we analyze intentions to buy and sell stocks and their relation to sentiment. As Kamstra, Kramer, and Levi (2012) note, the empirical evidence regarding the relation between mood and actual risk-taking behavior is complex. Isen (2011) elaborates that positive affect appears to decrease the perceived probability of losing, but at the same time increases the disutility of the potential loss. Based on the positive effect that (better) mood has on investor expectations, our hypothesis can be stated as:

H7: The larger the ISI (i.e., positive sentiment prevails), the higher the individual's tendency to buy rather than to sell stocks. 


\section{Empirical results}

Figure 1, which focuses on only one general sentiment-creating factor, demonstrates the main flavor of the results of this study. This figure draws the cumulative distribution functions (CDFs) of the next-month subjective return expectations corresponding to two groups of individuals. Group 1 consists of individuals who reported that they are "currently feeling great or good." Group 2 consists of those who reported that they are "currently feeling normal, bad or very bad."

[Please insert Figure 1 here]

According to economic models on rational behavior, investors establish their expected returns solely based on the economic facts at hand and sentiment is irrelevant in forming their estimates of future returns. Hence, we would expect only a random difference between the two groups' CDFs. However, Figure 1 reveals that the two CDFs do not intersect; there exists an FSD, where return expectations estimated by those who felt good are systematically higher than return expectations estimated by those who did not feel good. Thus, feeling good is associated with higher return expectations, and this result is intact for both the Dutch and U.S. markets. ${ }^{9}$ We now turn to more rigorous statistical analysis.

\section{A. Individual investor's return sentiment effects}

To analyze the effect of sentiment-creating factors on return expectations of individuals, we run the following Location-Scale, also known as Heterogeneous Choice, ordered probit regression (see, e.g., Harvey, 1976; Alvarez and Brehm, 1995):

\footnotetext{
${ }^{9}$ The FSD that is consistent with our hypotheses is also obtained when comparing the CDF of "Weather is good" versus the CDF of "Weather is normal or bad" and the CDF of "Sport result is bad" versus the CDF of "Sport result is normal or good." In contrast, when drawing the CDFs of the next-month subjective risk expectations, FSD is obtained only with the CDF of "Weather is bad" versus "Weather is normal or good." For the sake of brevity, these figures are not presented. For a detailed explanation of the FSD rule, see Levy (2006).
} 


$$
\begin{gathered}
E\left(R_{t+1, i}\right)=\beta_{0}+\sum_{j} \beta_{j} S E N T_{j, i}+\sum_{k} \beta_{k} \operatorname{CONTROLS_{k,i}}+\delta z_{i}+\varepsilon_{i}, \\
\operatorname{Var}\left(\varepsilon_{i}\right)=\left[\exp \left(\mathcal{Z}_{i}\right)\right]^{2},
\end{gathered}
$$

where $E\left(R_{t+1, i}\right)$ is the individual's subjective return expectation in the next period; $S E N T_{j, i}$ is one of the sentiment-creating variables, as defined in the previous section; $\operatorname{CONTROLS}_{k, i}$ are the control variables; and $z_{i}$ is the $i$ th individual variable.

The dependent variable in Equation (1) is the individual's next-month stock market return expectation, ranging from 1 (very low expectations) to 6 (very high expectations), as summarized in Table 2. To avoid biases, when the subject selects the non-quantitative choice "Don't know/no opinion," this observation is excluded from the regression. As a preliminary analysis, we also run a regression in which General-feeling is the dependent variable (see Test 1 in Table 3 below).

The main sentiment-creating variables $\left(S E N T_{j, i}\right)$ are the individual's General-feeling, Perceived-weather, SAD, and Sport-result. As we are interested in the effect of SAD as a function of the season of the year, rather than its all-year effect, we split this variable into three variables: $S A D$ reported by the individuals in the autumn wave (November), $S A D$ reported in the winter wave (February), and $S A D$ reported in the spring-summer wave (June). ${ }^{10}$

There are three groups of control variables. The "day-of-the-week" dummies control for any effect across the days of the week. The "market" control variables control for stock market conditions: Five-day return is equal to the return realized on the AEX index over the week preceding the date each subject completed the questionnaire, and VAEX is the AEX Volatility Index on that day, which, like the U.S. VIX, uses options prices to measure next-month expected

\footnotetext{
${ }^{10}$ The subjects are generally consistent in reporting on their attitude toward SAD across time: $61 \%$ of subjects report the same level of SAD in all three questionnaires and only $4 \%$ shift from not suffering (Choice 1) to suffering or severely suffering (Choices 3 and 4), or vice versa.
} 
volatility. The "individual" control variables control for the individuals' characteristics, which may systematically affect their attitude toward the stock market. Gender, Age, and Gross monthly income control for biases related to socioeconomic factors, and Education controls for individual financial expertise, which may be determined, at least partially, by education. ${ }^{11}$ Optimistic individuals may tend to both feel good and be optimistic with regard to the stock market, resulting in a spurious correlation between General-feeling and market expectations, which is not directly related to individual contemporaneous sentiment, but rather to personality in general. Therefore, Pessimistic-optimistic controls for individual pessimism-optimism tendencies in general. ${ }^{12}$

Finally, as we employ panel data, exogenous events may bias the results by simultaneously affecting the expectations of all subjects in each wave regardless of individual sentiments. For example, the end of the Federal Reserve's program of QE2 in June 2011 probably affected the expectations of all subjects, who completed the third-wave questionnaire in June. Moreover, as the same individuals filled out up to three questionnaires, we control for both autocorrelation and heteroskedasticity. ${ }^{13}$ Therefore, Equation (1) includes three fixed effects variables across time and subjects. "Questionnaire-wave" is a nominal three-category variable that controls for time trends by allowing for a different threshold at each wave. The "ith individual" $\left(z_{i}\right)$ is a nominal 577-category variable that controls for cross-individual fixed effects. Finally, to account for heteroskedasticity (that is, the possibility of differing variability across

\footnotetext{
${ }^{11}$ The following control variables are found to be insignificant in all tests, and are therefore excluded from the regressions: marital status, number of children living at home, rural vs. urban dwelling, and occupation.

${ }^{12}$ The subjects are consistent in reporting their tendency toward optimism across time: $57 \%$ of subjects report the same optimism-pessimism tendency in all three questionnaires and only 2\% shift from pessimism (Choices 1 and 2) to optimism (Choices 4 and 5) or vice versa.

${ }^{13}$ In addition, we first check that this procedure does not use identical observations three times. This is not the case and the subjects reveal different and generally uncorrelated expectations across time. For example, the Spearman's correlation coefficients corresponding to the next-month return expectations on the AEX index are $0.25,0.15$, and 0.32 , for the three possible pairs of waves, respectively.
} 
individuals), we use the Location-Scale model, where the coefficients corresponding to each individual are "scaled" by that individual's choice variability over time, as measured by the ith individual scale variable. Other potential scale variables, including a questionnaire wave scale variable, are found to be insignificant, and are therefore excluded from the regression.

Our sentiment hypotheses assert that the sentiment-creating variables affect mood, which, in turn, affects expectations. Therefore, we first explore whether the sentiment-creating variables indeed affect General-feeling, which serves in this test as a proxy for individual contemporaneous mood. Regression 1 in Table 3 reports the result of regressing individual mood (General-feeling) on the same explanatory variables and using the same methodology as in Equation (1).

\section{[Please insert Table 3 here]}

The Perceived-weather coefficient is significantly positive and large. Recalling that high category denotes good feeling as well as good weather, the positive coefficient implies that the better the weather from the individual's point of view, the better the individual's general feeling. The $S A D$ coefficients corresponding to autumn and winter are significantly negative and relatively large in absolute terms $(-0.33$ and -0.28 , respectively). Thus, as expected, the mood of SAD sufferers is lower than that of non-SAD sufferers in the winter and particularly in the autumn. Finally, the Sport-result coefficient is insignificant, a result that may be affected the relatively small number of sports fans in the sample (about $25 \%$ of observations).

In testing the day-of-the-week effect on mood, the omitted variable is Saturday, which is characterized by the highest mood on average. Apart from the Sunday coefficient, which is insignificant, all other coefficients are significantly negative. Thus, the mood of individuals who filled out the questionnaire on weekdays is lower than that of individuals who completed the 
questionnaire on Saturdays. In contrast, there is no significant difference in mood on Sundays and Saturdays (that is, on the weekend). Thus, in line with psychological theory, reported mood is better on weekends than on weekdays.

The Pessimistic-optimistic coefficient is significantly positive, suggesting that individuals who describe themselves as optimistic are generally in a better mood than other individuals. Finally, the $i$ th individual coefficients are insignificant, indicating that, apart from the difference implied by the general pessimism-optimism tendency, there are no significant differences in mood across individuals.

The consistency of the results obtained from Regression 1 with the psychological literature regarding $\mathrm{SAD}$, the relatively high positive mood on weekends, and the positive correlation between mood and optimism tendency, all indicate that the sentiment-creating variables indeed measure what they are supposed to measure. This result improves confidence in the accuracy and quality of our data. Let us turn to the core hypotheses of this study: the effects of sentiment-creating factors on return and risk expectations and on investment plans.

Apart from the first column in Table 3, all other reported results in this table relate to Equation (1), which in Table 3 is denoted Regression 2. We thus focus hereafter on regressions in which the dependent variable is next-month expected return with respect to the AEX index. In these regressions, General-feeling is considered another sentiment variable, as we find that it does not fully capture the sentiment components in the other sentiment-creating variables. ${ }^{14}$

If the mood-return expectations hypotheses hold, we would expect positive coefficients in regressions where return expectations are the dependent variable. Indeed, in line with the individual sentiment hypotheses ( $\mathrm{H} 1$ and $\mathrm{H} 4)$, the coefficients in Test 2 corresponding to

\footnotetext{
14 The Spearman's correlation coefficients between this variable and the other sentiment-creating variables are relatively low: they are smaller than 0.20 in all cases.
} 
General-feeling and Sport-result are significantly positive. Thus, the better the individual's general feeling and the better the perceived performance of the individual's favorite sports team, the higher the individual's return expectations. This finding is in line with the laboratory result of Nygren, Isen, Taylor, and Dulin (1996), showing that positive affect leads to more optimistic expectations regarding the probability of winning. These results are not induced by effects related to the questionnaire wave, day-of-the-week, stock market conditions, gender, income, age, education of the individual, or the individual's tendency toward optimism, as we control for all these factors. Further, to account for a possible multicollinearity, we also run the regression with each sentiment-creating variable separately. The results of these tests are nearly identical to those in Test 2 (where only the Sport-result coefficient is slightly more significant, at $p=0.04$ ), and therefore they are not reported.

In contrast, the coefficient corresponding to Perceived-weather is positive but small and insignificant. Thus, we do not find that perceived weather is significantly correlated with expected returns. Therefore, the weather hypothesis $(\mathrm{H} 2)$ is rejected. ${ }^{15}$

The $S A D$ in the autumn coefficient in Test 2 is negative and insignificant, whereas the SAD coefficients corresponding to the winter and spring-summer are significantly positive. Thus, we obtain a first indication that more intensive SAD in the autumn is accompanied by lower subjective expected return, although the result is not significant. The regression coefficients corresponding to SAD provide an indication of the SAD effect but do not directly test the SAD hypothesis (H3), because this hypothesis corresponds only to SAD sufferers while

\footnotetext{
${ }^{15}$ A plausible reason for this result is the fact that weather and mood are associated in a non-linear, complex manner. For example, while higher temperature is associated with improved mood (Howarth and Hoffman, 1984), very high temperature is associated with bad mood and this tendency also depends on the season of the year and the exposure to outdoor weather (Keller, Frederickson, Ybarra, Cote, Johnson, Mikels, Conway, and Wager, 2005). In unreported tests we find supporting evidence for this possibility, as expected returns are significantly correlated with perceived weather at the extremes (i.e., when weather is very good or very bad).
} 
the regression includes all individuals. The more important test, which corresponds only to SAD sufferers and directly tests the SAD hypothesis (H3), compares the SAD coefficients during the various seasons of the year. We find that for SAD sufferers, the null hypotheses of equal coefficients corresponding to $S A D$ in the autumn and $S A D$ in the winter or $S A D$ in the springsummer are rejected (Wald test statistics of 4.93 and 4.68, respectively, where in both cases $p<0.05)$. This result and the negative sign of the $S A D$ in the autumn coefficient imply that SAD sufferers have significantly lower return expectations in the autumn compared to other seasons. In contrast, the null hypothesis of equal coefficients corresponding to $S A D$ in the winter and $S A D$ in the spring-summer is not rejected (Wald test statistic of 0.10). Thus, in line with the SAD hypothesis (H3) and the results of Kamstra, Kramer, and Levi (2003), the return expectations reported by SAD sufferers are significantly lower in the autumn than the expectations they report in the winter and the spring-summer. ${ }^{16}$

To sum up, the results of Tests 2 and 3 confirm the SAD hypothesis (H3) as well as the results of Kamstra, Kramer, and Levi (2003); return expectations of SAD sufferers exhibit a significant seasonality that coincides with the seasonality in SAD.

The Monday coefficient in Test 2 is significantly positive, suggesting that return expectations are highest on Mondays. ${ }^{17}$ Coefficients for the other days are insignificant. Thus, the day-of-the-week mood effect in Test 1, which is consistent with the first part of the sentiment hypothesis (H5) and with the psychological literature, does not translate into return expectations, hence the second part of the day-of-the-week sentiment hypothesis (H5) is rejected.

\footnotetext{
${ }^{16}$ As a robustness check, in an unreported test, we replaced the SAD variables with spring-preference variables, which test for SAD indirectly. The spring-preference coefficients corresponding to the autumn and winter are significantly negative and positive, respectively, suggesting that those who prefer spring reveal low return expectations in the autumn. Moreover, the hypothesis of equal coefficients for Spring-preference in the autumn and Spring-preference in the winter is rejected (Wald test statistic of $16.60, p<0.001$ ). Thus, similar to the SAD variables, the return expectations corresponding to individuals who prefer spring over autumn (which obviously include the SAD-sufferers) are significantly lower in autumn than in winter.

${ }^{17}$ In an unreported test, we find that this result is particularly profound on Monday mornings.
} 
Several control variables in Test 2 are also significant. First, the Questionnaire-wave coefficient is highly significant. This result is likely related to the negative time trend induced by the end of the Federal Reserve's program of QE2, accompanied by a stream of weak macroeconomic data in the U.S. and, in particular, in Europe. This result shows that individuals in the sample are knowledgeable about the stock market. Individual investors' knowledge of the market is also evident in the positive and negative coefficients corresponding to the five-dayreturn and volatility (VAEX) control variables, respectively, where the latter is also significant. Similarly, the significantly negative education coefficient suggests that better-educated individuals are more familiar with international economic news, which was mainly negative in the sample period. Finally, the individual scale variable is highly significant, indicating significant variability in expectations across individuals.

According to psychology theory, the effects of positive and negative moods on return expectations are not necessarily symmetrical. Test 3, reported in Table 3, examines asymmetry in the sentiment effects, by introducing for each sentiment-creating variable two dummies, which are equal to 1 for good or bad categories, respectively, 0 otherwise. While the good and bad Sport-result coefficients are insignificantly positive and negative and of the same magnitude in absolute terms and the good and bad Perceived-weather coefficients are negative, very small, and insignificant, the General-feeling good coefficient is significantly positive and the Generalfeeling bad coefficient is negative, small, and insignificant. However, no significant asymmetry is found even with General-feeling, as the null hypothesis that the absolute values of each pair of coefficients in good and bad states are equal is not rejected. 


\section{B. Aggregate sentiment results}

A natural question that emerges from the results obtained thus far is how broad are the sentiment effects. Are the effects unique to the domestic Dutch market? Are the effects the same for short-term and long-term expectations? Table 4 reports the results from tests that explore these questions and it addresses what effect sentiment has on expected risk.

As a preliminary test, we find that the Pearson's correlation coefficients between shortterm and long-term return expectations in the Dutch and the U.S. markets are 0.50 and 0.59 , respectively, and they are 0.57 and 0.71 in regard to volatility expectations, where in all cases $p<0.001 .^{18}$ Thus, individual investors are generally consistent in their short-term and long-term return and risk expectations, in regard to both the domestic Dutch market and the foreign U.S. market.

To avoid unnecessary repetition by testing each sentiment-creating variable separately, and to generalize our sentiment results, in Table 4 we replace the various sentiment-creating variables in Equation (1) with a comprehensive $I S I .{ }^{19} I S I$ is constructed from the first principal components of the correlation matrix of the sentiment-creating variables that have been previously found to significantly affect return expectations as follows: ${ }^{20}$

$$
\begin{gathered}
I S I=0.611 \times \text { General-feeling }-0.845 \times S A D \text { in the autumn }+0.152 \times S A D \text { in the winter }+ \\
0.253 \times S A D \text { in the spring-summer }+0.113 \times \text { Sport-result }
\end{gathered}
$$

Tests 1 and 2 in Table 4 correspond to the case in which the dependent variable is nextmonth and next-year domestic stock return expectations, respectively. The ISI coefficients in

\footnotetext{
${ }^{18}$ ANOVA analysis of short-term and long-term expectations for the Dutch market reveals $F$-statistics of 81.1 and $158.4(p<0.001)$ for return and risk expectations, respectively.

${ }^{19}$ As previously mentioned, although General-feeling is affected by the other sentiment-creating variables, it does not capture the entire effect of the other variables (see Footnote 14). Therefore, ISI is a more comprehensive measure for sentiment than General-feeling.

${ }^{20}$ As Perceived-weather is not found to be related to return expectations, this variable is excluded from the analysis.
} 
these two tests are positive, but significant only with regard to next-month expectations. Thus, we find that the higher the ISI (or the more positive the sentiment), the higher the return expectations, though only for short-term expectations is the ISI found to be statistically significant.

[Please insert Table 4 here]

In Tests 3 and 4, the dependent variable is next-month and next-year domestic risk expectations, respectively. Expected risk is measured in terms of risk relative to the average risk, and is ordered from low risk (Choice 1) to high risk (Choice 5). Here, the ISI coefficients are both negative but insignificant. Thus, a higher ISI tends to be accompanied by lower risk expectations, but this result is not significant.

The VAEX coefficients are significantly negative in Tests 1 and 2 and significantly positive in Tests 3 and 4, indicating that higher implied volatility in the options market is not only accompanied by lower return expectations but also by higher risk expectations. Finally, the Monday coefficients are positive in Tests 1 and 2 and negative in Tests 3 and 4, but only in Test 1 is the coefficient significant at the 5\% level. Thus, only short-term expected returns are significantly correlated with Mondays.

Tests 5-8 repeat Tests 1-4 for expectations corresponding to the U.S. S\&P 500 Index. The sentiment effect results in these tests are similar to those in Tests $1-4$, with sentiment positively affecting return expectations and negatively affecting risk expectations, where here the long-term risk and return expectations are also significant. Thus, the sentiment effect is intact for expectations regarding the foreign (U.S.) market.

To summarize, both short-term and long-term expectations are in the same direction and consistent with our sentiment hypothesis, but these results are significant mainly with regard to 
return expectations. In all four regressions of expected returns, sentiment coefficients are positive, and three out of four are statistically significant. For the risk expectations, in all four regressions sentiment coefficients are negative, but only one coefficient is significant.

\section{Individual sentiment and investment plans}

Table 5 reports results of the regression in Equation (1), where the dependent variable is the individual's investment plan for the coming month, which ranges from 1, for a plan only to sell stocks, to 5 , for a plan only to buy stocks. Tests 1 and 2 explore whether stock market expectations affect trading plans, by including as explanatory variables expected return and risk in the next month and next year, respectively. As expected of subjects making rational investment decisions, the return expectations coefficients are positive and significant in both tests, suggesting that higher return expectations are positively correlated with plans to buy rather than sell stocks. However, the risk coefficients are insignificant, potentially suggesting that individual decisions to invest are primarily motivated by expected market returns.

[Please Insert Table 5 here]

Having established that individuals rely on rational economic factors (such as expected returns) when making investment decisions, we turn to testing our hypothesis regarding the impact that non-economic sentiment has on investment decisions. As the individual's expectations are also affected by sentiment, the correlation between expectations and investment plans implies that sentiment's effect on expectations may in turn affect investment plans. To directly test this hypothesis, in Test 3 in Table 5, the individual's investment plans for the coming month serve as the dependent variable, and the control variables are identical to those in 
Table 3. The ISI coefficient in Test 3 is significantly positive, suggesting that higher sentiment does indeed increase individuals' reported intentions to buy rather than to sell stocks.

Test 4 repeats Test 3 while including a recent-trading-activity control variable ranging from 1 (only sold stocks in the previous month) to 5 (only bought stocks in the previous month). This variable controls for any long-term investment program of the individual, for example, if the individual invests in stocks on a regular basis. Indeed, the recent-trading-activity coefficient is significantly positive, implying that individuals' plans are generally consistent with their recent trades. Further, the ISI coefficient is virtually identical to that in Test 3, suggesting that sentiment's effect on trading plans is robust after controlling for recent trades.

For consistency, in Tests 1-4 in Table 5, subjects who reported that they did not plan to trade in the coming month are included in the "neutral" category of those who reported that they planned to buy and sell the same amount of stock. To test the robustness of the results to this procedure, in Test 5 these subjects are excluded from the regression, which now includes only individuals who reported that they planned to trade in the coming month. The ISI coefficient in Test 5 is larger than the coefficient in Test 4 and is also significant, despite the substantially smaller number of observations (217 rather than 1,156). These tests confirm H7 that positive sentiment leads to a tendency to buy rather than sell stocks among individual investors.

Finally, none of the weekday coefficients is statistically significant. Thus, after individually controlling for both return expectations and sentiment, we do not find that Mondays have additional effects on investment plans. 


\section{Concluding remarks}

Since the famous experiment of Allais (1953), it has been extensively documented that many subjects participating in laboratory experiments make irrational choices, contradictory choices, and choices that contradict expected utility. Empirical studies also suggest that investors behave irrationally; stock prices are correlated with non-economic factors such as weather conditions, season of the year, sporting events, and so forth.

In this study, we test at the individual level the relation between various sentimentcreating factors (which contribute to mood and general feelings) and subjective return and risk expectations, as well as the investment plans of individuals who actually invest in the stock market. This study is based on approximately 5,000 households, a representative sample of the population of the Netherlands, and the statistical analyses are based on 1,465 questionnaires completed by individual investors. As the survey took place in three different seasons, we are also able to test the effect of SAD on subjective estimates of return and risk.

We find that the happier the subject, the more optimistic the subject is with regard to the domestic Dutch stock market as well as the U.S. stock market. Specifically, we find that the better the general mood of the individual and the better the results of the individual's favorite sports team in the days just prior to the completion date of the questionnaire, the higher the individual's stock market return expectations. We combine these individual factors into one sentiment index and find that positive overall sentiment leads to higher expected returns and lower expected risk. The return effect is more profound and significant in most cases, while the risk effect is in the expected direction but significant only in one case. SAD, which is found to be correlated with mood, also affects return expectations. The coefficients of SAD sufferers corresponding to the various seasons of the year are significantly different. This information, 
coupled with the fact that the SAD coefficient is negative in the autumn, indicates that SAD sufferers have lower expected returns in the autumn than in other seasons of the year. Thus, SAD is an important factor in forming subjective expectations. Finally, consistent with previous psychological research on the day-of-the-week effect, the general mood on weekdays is lower than that on the weekends. However, this lower mood on weekdays is not accompanied by lower return expectations.

While some of the results conform to intuition, the intensity of the phenomenon is quite surprising. For example, the cumulative distribution of expected returns of those who feel good is strongly shifted to the right in comparison to the distribution of those who feel bad. Hence, there is FSD of the expected return distributions induced by the feelings of individuals, rather than only a mean effect. 


\section{References}

Allais, M. "Le Comportement de l'Homme Rationnel Devant le Risque: Critique des Postulats et Axiomes de l'École Américaine.” Econometrica, 21 (1953), 503-546.

Alvarez, R. M., and J. Brehm. “American Ambivalence Towards Abortion Policy: Development of a Heteroskedastic Probit Model of Competing Values." American Journal of Political Science, 39 (1995), 1055-1082.

Ashby, F. G., A. M. Isen, and A. U. Turken. "A Neuropsychological Theory of Positive Affect and Its Influence on Cognition.”Psychological Review, 106 (1999), 529-550.

Ashton, J. K., B. Gerrard, and R. Hudson. "Economic Impact of National Sporting Success: Evidence from the London Stock Exchange.” Applied Economics Letters, 10 (2003), 783-785.

Baker, M., and J. Wurgler. "Investor Sentiment in the Stock Market." Journal of Economic Perspectives, 21 (2007), 129-151.

Bellemaere, C., S. Kröger, and A. van Soest. "Measuring Inequity Aversion in a Heterogeneous Population Using Experimental Decisions and Subjective Probabilities." Econometrica, 76 (2008), 815-839.

Cao, M., and J. Wei. "Stock Market Returns: A Note on Temperature Anomaly." Journal of Banking and Finance, 29 (2005), 1559-1573.

Dolvin, S. D., and M. K. Pyles. "Seasonal Affective Disorder and the Pricing of IPOs." Review of Accounting and Finance, 6 (2007), 214-228.

Dolvin, S. D., M. K. Pyles, and Q. Wu. "Analysts Get SAD too: The Effect of Seasonal Affective Disorder on Stock Analysts' Earnings Estimates.” Journal of Behavioral Finance, 10 (2009), 214-225. 
Dreisbach, G., and T. Goschke. "How Positive Affect Modulates Cognitive Control: Reduced Perseveration at the Cost of Increased Distractibility." Journal of Experimental Psychology: Learning, Memory, and Cognition, 30 (2004), 343-353.

Edmans, A., D. García, and O. Norli. "Sports Sentiment and Stock Returns." The Journal of Finance, 62 (2007), 1967-1998.

Egloff, B., A. Tausch, C.-W. Kohlmann, and H. W. Krohne. "Relationships Between Time of Day, Day of the Week, and Positive Mood: Exploring the Role of the Mood Measure." Motivation and Emotion, 19 (1995), 99-110.

Etzioni, A. "Normative-affective Factors: Toward a New Decision-Making Model." Journal of Economic Psychology, 9 (1988), 125-150.

Goetzmann, W. N., and N. Zhu. "Rain or Shine: Where Is the Weather Effect?" European Financial Management, 11 (2005), 559-578.

Graham, J. R., C. R. Harvey, and H. Huang. "Investor Competence, Trading Frequency, and Home Bias.” Management Science, 55 (2009), 1094-1106.

Guiso, L., P. Sapienza, and L. Zingales. "Trusting the Stock Market." The Journal of Finance, 63 (2008), 2557-2600.

Hanoch, Y. "“Neither an Angel nor an Ant': Emotion as an Aid to Bounded Rationality." Journal of Economic Psychology, 23 (2002), 1-25.

Harvey, A. C., "Estimating Regression Models with Multiplicative Heteroscedasticity." Econometrica, 44 (1976), 461-465.

Helliwell, J. F., and S. Wang. "Weekends and Subjective Well-Being." NBER Working Paper No. 17180 (2011). 
Hirshleifer, D., and T. Shumway. "Good Day Sunshine: Stock Returns and the Weather." The Journal of Finance, 58 (2003), 1009-1032.

Howarth, E., and M. S. Hoffman. "A Multidimensional Approach to the Relationship Between Mood and Weather.” British Journal of Psychology, 75 (1984), 15-23.

Isen, A. M. "A Role for Neuropsychology in Understanding the Facilitating Influence of Positive Affect on Social Behavior and Cognitive Processes." In The Oxford Handbook of Positive Psychology, S. J. Lopez and C. R. Snyder, eds. New York: Oxford University Press (2011), 503518.

Johnson, E. J. and A. Tversky. "Affect, Generalization, and the Perception of Risk." Journal of Personality and Social Psychology, 45 (1983), 20-31.

Kamstra, M. J., L. A. Kramer, and M. D. Levi. "Winter Blues: A SAD Stock Market Cycle.” The American Economic Review, 93 (2003), 324-343.

Kamstra, M. J., L. A. Kramer, and M. D. Levi. "Seasonal Variation in Treasury Returns." Rotman School of Management Working Paper No. 1076644 (2011).

Kamstra, M., L. A. Kramer, and M. D. Levi. "A Careful Re-Examination of Seasonality in International Stock Markets: Comment on Sentiment and Stock Returns.” Journal of Banking and Finance, 36 (2012), 934-956.

Kamstra, M. J., L. A. Kramer, M. D. Levi, and R. Wermers. "Seasonal Asset Allocation: Evidence from Mutual Fund Flows.” Working Paper, University of Maryland (2011).

Kaplanski, G., and H. Levy. "Sentiment and Stock Prices: The Case of Aviation Disasters." Journal of Financial Economics, 95 (2010a), 174-201. 
Kaplanski, G., and H. Levy. "Exploitable Predictable Irrationality: The FIFA World Cup Effect on the U.S. Stock Market.” Journal of Financial and Quantitative Analysis, 45 (2010b), 535553.

Keller, M. C., B. L. Fredrickson, O. Ybarra, S. Cote, K. Johnson, J. Mikels, A. Conway, and T. Wager. “A Warm Heart and a Clear Head.” Psychological Science, 16 (2005), 724-731.

Kramer, L., and J. M. Weber. "This Is Your Portfolio on Winter: Seasonal Affective Disorder and Risk Aversion in Financial Decision Making." Social Psychological and Personality Science, 3, (2012), 193-199.

Levy, H. "Stochastic Dominance: Investment Decision-Making Under Uncertainty." Kluwer Academic Publishers, Amsterdam (2006).

Lo, K., and S. S. Wu. "The Impact of Seasonal Affective Disorder on Financial Analysts and Equity Market Returns.” Working Paper, University of British Columbia (2008).

Mehra, R., and R. Sah. "Mood Fluctuations, Projection Bias and Volatility of Equity Prices." Journal of Economic Dynamics and Control, 26 (2002), 869-887.

Mersch, P. P. A., H. M. Middendorp, A. L. Bouhuys, D. G. M. Beersma, and R. H. van den Hoofdakker. "Seasonal Affective Disorder and Latitude: A Review of the Literature." Journal of Affective Disorders, 53 (1999), 35-48.

Mitchell, R. L. C., and L. H. Phillips. "The Psychological, Neurochemical and Functional Neuroanatomical Mediators of the Effects of Positive and Negative Mood on Executive Functions." Neuropsychologia, 45 (2007), 617-629. 
Nygren, T. E., A. M. Isen, P. J. Taylor, and J. Dulin. "The Influence of Positive Affect on the Decision Rule in Risk Situations: Focus on Outcome (and Especially Avoidance of Loss) Rather than Probability." Organizational Behavior and Human Decision Processes, 66 (1996), 59-72.

Pardo, A., and E. Valor. "Spanish Stock Returns: Where Is the Weather Effect?" European Financial Management, 9 (2003), 117-126.

Saunders, E. M. "Stock Prices and Wall Street Weather." The American Economic Review, 83 (1993), 1337-1345.

Scherpenzeel, A., and M. Das. “"True’ Longitudinal and Probability-Based Internet Panels.” In Social and Behavioral Research and the Internet: Advances in Applied Methods and Research Strategies, M. Das, P. Ester, and L. Kaczmirek, eds. Boca Raton: Taylor and Francis (2010), 77103.

Van Rooij, M., A. Lusardi, and R. Alessie. "Financial Literacy and Stock Market Participation." Journal of Financial Economics, 101 (2011), 449-472.

Veld, C., and Y. V. Veld-Merkoulova. "The Risk Perceptions of Individual Investors." Journal of Economic Psychology, 29 (2008), 226-252.

Von Gaudecker, H.-M., A. van Soest, and E. Wengström. "Heterogeneity in Risky Choice Behavior in a Broad Population.” The American Economic Review, 101 (2011), 664-694. 


\section{Currently feeling good (Choices 4 and 5)}

100.0\%- Currently feeling normal or bad (Choices 1, 2, and 3)

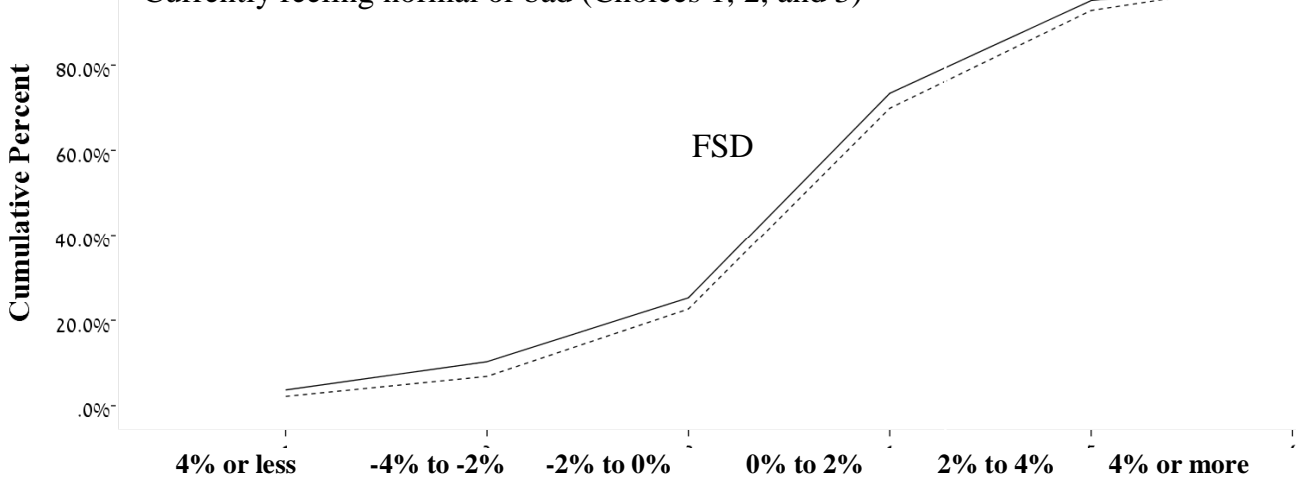

$1 \mathrm{~b}$

Next month return expectations (Dutch market)

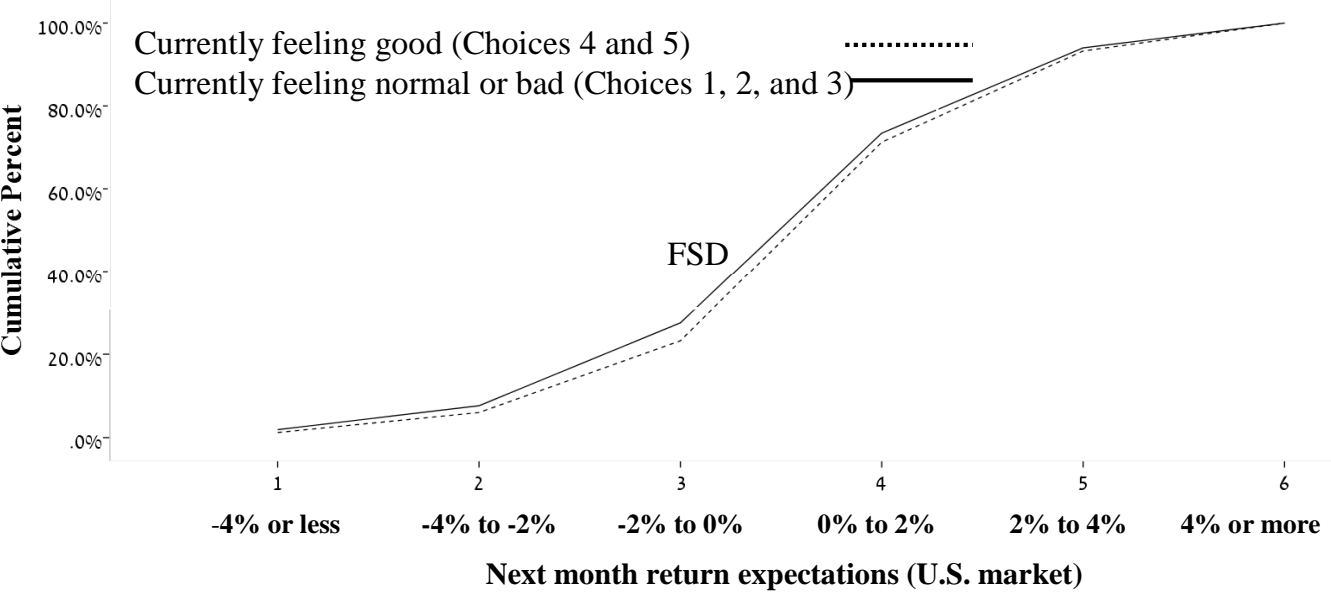

Figure 1. General feeling and subjective return expectations

Figures 1a and $1 \mathrm{~b}$ compare the cumulative distribution functions (CDFs) of next-month subjective return expectations corresponding to individuals categorized by their contemporaneous general feeling. The subjective expectations in Figures 1a and $1 \mathrm{~b}$ correspond to the expected returns on the Dutch AEX Index and the U.S. S\&P 500 Index, respectively. 
Table 1. Sample characteristics

This table reports descriptive statistics of the sample population. Panel A reports the number of individuals approached and the number of individuals who completed the questionnaire in each wave. Panel B reports the demographic characteristics of the sample, which is composed of the 577 individuals who have held stocks in their portfolio and submitted at least 1 completed questionnaire. Panel C reports the financial characteristics of those 577 individuals.

\begin{tabular}{|c|c|c|c|c|}
\hline \multicolumn{5}{|c|}{ A. Sample population } \\
\hline & Total approached $^{1}$ & $\begin{array}{c}\text { Complete } \\
\text { questionnaire }\end{array}$ & $\begin{array}{c}\text { Incomplete } \\
\text { questionnaire }\end{array}$ & No response \\
\hline $\begin{array}{l}\text { A. Preliminary screening round: } \\
\text { Held stocks in October } 2010 \text { (the sample) }\end{array}$ & 7,428 & $\begin{array}{c}5,316 \\
929\end{array}$ & 0 & 2,112 \\
\hline B1. Wave 1 in November 2010 & 929 & 755 & 124 & 50 \\
\hline B2. Wave 2 in February 2011 & 918 & 714 & 108 & 96 \\
\hline B3. Wave 3 in June 2011 & 804 & 612 & 64 & 128 \\
\hline $\begin{array}{l}\text { Total in all three waves } \\
\text { Missing personal data }\end{array}$ & 2,651 & $\begin{array}{c}2,081 \\
616 \\
\end{array}$ & 296 & 274 \\
\hline Total complete reliable observations & & 1,465 & (filled by 577 individuals) & \\
\hline
\end{tabular}

B. Demographic characteristics

\begin{tabular}{|c|c|c|c|c|c|c|c|c|c|c|c|c|c|}
\hline \multicolumn{2}{|c|}{ Gender } & \multicolumn{2}{|c|}{$\begin{array}{l}\text { Have a } \\
\text { spouse }\end{array}$} & \multicolumn{2}{|c|}{$\begin{array}{c}\text { Degree of } \\
\text { urbanization }\end{array}$} & \multicolumn{2}{|l|}{ Education } & \multicolumn{2}{|c|}{ Occupation } & \multicolumn{2}{|c|}{ Age } & \multicolumn{2}{|c|}{$\begin{array}{c}\text { Number of } \\
\text { children at } \\
\text { home }\end{array}$} \\
\hline Male & 374 & Yes & 453 & Very high & 76 & Primary & 24 & Employed & 286 & $15-24$ & 16 & 0 & 369 \\
\hline \multirow[t]{7}{*}{ Female } & 203 & No & 124 & High & 162 & High S. (vocational) & 96 & Retired & 148 & $25-34$ & 34 & 1 & 46 \\
\hline & & & & Moderate & 132 & High S. (general) & 64 & Self-employed & 41 & $35-44$ & 81 & 2 & 106 \\
\hline & & & & Low & 116 & Vocational & 85 & Homemaker & 6 & $45-54$ & 132 & 3 & 52 \\
\hline & & & & Not urban & 91 & College & 199 & Unfit for work & 21 & $55-64$ & 171 & 4 & 4 \\
\hline & & & & & & University & 109 & Student & 15 & $65+$ & 143 & & \\
\hline & & & & & & & & Unemployed & 47 & & & & \\
\hline & & & & & & & & Volunteer & 13 & & & & \\
\hline Total & 577 & & 577 & & 577 & & 577 & & 577 & & 577 & & 577 \\
\hline
\end{tabular}

\section{$\underline{\text { C. Financial characteristics }}$}

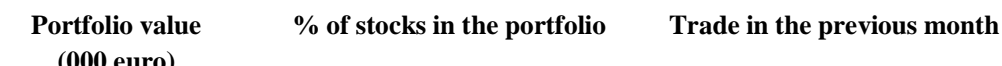

\section{Gross monthly Type of housing} personal income

$\begin{array}{ccc}0 & \text { (000 euro) }\end{array}$

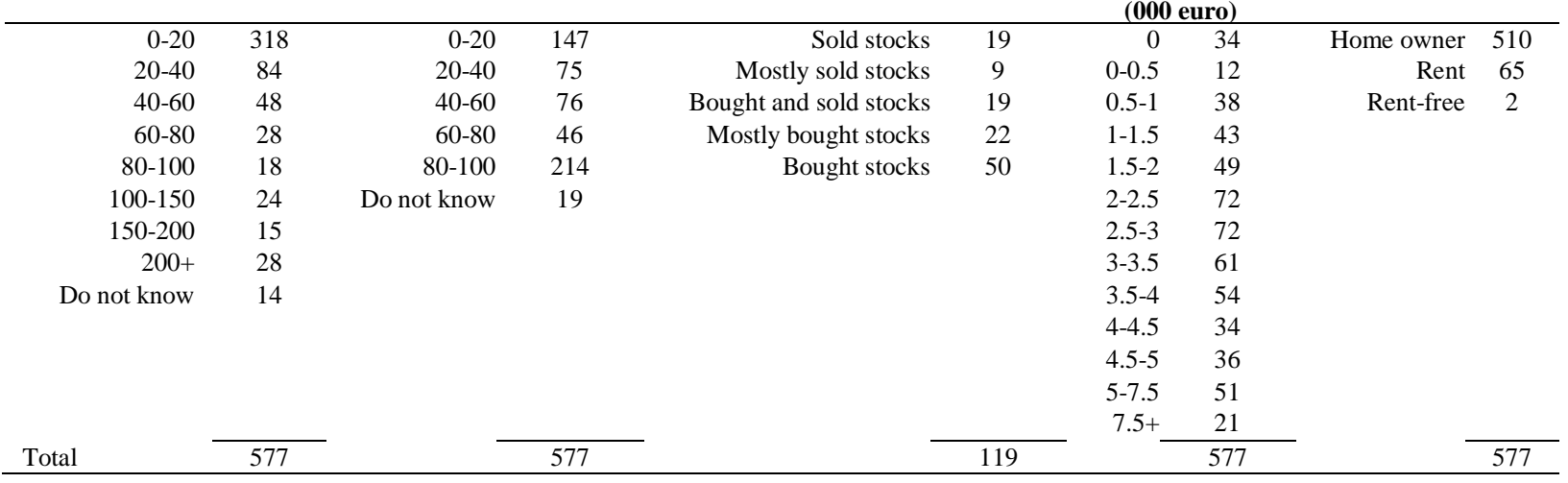


Table 2. Descriptive statistics of expectations and sentiment-creating variables

Table 2 reports the descriptive statistics of the main variables employed in this study. The total number of observations from all three rounds is 1,465 questionnaires complete with personal data, which were completed by 577 individuals. The AEX and S\&P correspond to the Dutch AEX Index and the U.S. S\&P 500 Index.

A. Subjective expectations and trading activity

Individuals' beliefs about future returns and risk

Next-month return expectations Next-year return expectations Next-month risk expectations Next-year risk expectations

Investment activity

Past Future
trading plans

\begin{tabular}{|c|c|c|c|c|c|c|c|c|c|c|c|c|c|}
\hline \multirow{2}{*}{ Choice } & \multirow{2}{*}{$\underline{\mathrm{AEX}}$} & \multirow{2}{*}{$\underline{\text { S\&P } 500}$} & \multirow{2}{*}{ Choice } & \multirow{2}{*}{$\underline{\mathrm{AEX}}$} & \multirow{2}{*}{$\underline{\text { S\&P } 500}$} & \multirow{2}{*}{ Choice } & \multirow[b]{2}{*}{$\underline{\mathrm{AEX}}$} & \multirow{2}{*}{$\underline{\text { S\&P 500 }}$} & \multirow{2}{*}{$\underline{\mathrm{AEX}}$} & \multirow{2}{*}{$\underline{\mathrm{S} \& \mathrm{P} 500}$} & \\
\hline & & & & & & & & & & & Choice & & \\
\hline$\overline{1 .(-4 \%}$ or less $)$ & $\overline{33}$ & 15 & $\overline{1 .(-15 \% \text { or less })}$ & $\overline{4}$ & 2 & $\overline{1 . ~ M u c h ~ l e s s ~ r i s k y ~}$ & $\overline{11}$ & 9 & $\overline{18}$ & 15 & $\overline{1 . \text { Only sell }}$ & 56 & 33 \\
\hline 2. $(-4 \%$ to $-2 \%)$ & 64 & 51 & 2. $(-15 \%$ to $-10 \%)$ & 5 & 6 & 2. Somewhat less risky & 222 & 166 & 341 & 218 & 2. Mostly sell & 15 & 22 \\
\hline 3. $(-2 \%$ to $0 \%)$ & 178 & 180 & 3. $(-10 \%$ to $-5 \%)$ & 21 & 24 & 3. Average risk & 594 & 455 & 462 & 379 & 3. Buy and sell & 57 & 34 \\
\hline 4. $(0 \%$ to $2 \%)$ & 551 & 463 & 4. $(-5 \%$ to $0 \%)$ & 103 & 135 & 4. Somewhat riskier & 276 & 300 & 285 & 279 & 4. Mostly buy & 56 & 35 \\
\hline 5. $(2 \%$ to $4 \%)$ & 259 & 210 & 5. $(0 \%$ to $5 \%)$ & 654 & 521 & 5. Much riskier & 55 & 61 & 67 & 86 & 5. Only buy & 126 & 93 \\
\hline 6. ( $4 \%$ or more) & 71 & 63 & 6. $(5 \%$ to $10 \%)$ & 324 & 226 & Total valid & 1,158 & 991 & 1,173 & 977 & Total valid & 310 & 217 \\
\hline Total valid & 1,156 & 982 & 7. $(10 \%$ to $15 \%)$ & 57 & 47 & Don't know & 307 & 474 & 292 & 488 & Not active & 1,155 & 1,248 \\
\hline Don't know & 309 & 483 & 8. $(15 \%$ or more $)$ & 16 & 13 & Total & 1,465 & 1,465 & 1,465 & 1,465 & Total & 1,465 & 1,465 \\
\hline \multirow[t]{3}{*}{ Total } & 1,465 & 1,465 & Total valid & 1,184 & 974 & & & & & & & & \\
\hline & & & Don't know & 281 & 491 & & & & & & & & \\
\hline & & & Total & 1,465 & 1,465 & & & & & & & & \\
\hline \multicolumn{14}{|c|}{ Valid choices statistics } \\
\hline Mean choice & 4.00 & 4.01 & & 5.26 & 5.15 & & 3.12 & 3.24 & 3.04 & 3.21 & & 2.42 & 2.39 \\
\hline Median choice & 4.00 & 4.00 & & 5.00 & 5.00 & & 3.00 & 3.00 & 3.00 & 3.00 & & 2.00 & 2.00 \\
\hline Std. dev. & 1.05 & 1.00 & & 0.88 & 0.92 & & 0.80 & 0.83 & 0.91 & 0.94 & & 1.50 & 1.49 \\
\hline
\end{tabular}

B. Sentiment-creating factors and control variables

\begin{tabular}{|c|c|c|c|c|c|c|c|c|c|c|c|c|c|}
\hline & & & & Sentiment- & reating & g variables & & & & & Cont & rol variables & \\
\hline General-fee & & Perceived- & ather & Suffering from & AD & $\begin{array}{r}\text { Spring-autum } \\
\text { preference }\end{array}$ & & $\begin{array}{r}\text { Favorite sport t } \\
\text { performanc }\end{array}$ & & $\begin{array}{r}\text { Questionn } \\
\text { filling d: }\end{array}$ & aire & Pessimistic-optin & istic \\
\hline Choice & & Choice & & Choice & & Choice & & Choice & & Day & & Choice & \\
\hline$\overline{1 . \text { Very bad }}$ & 5 & $\overline{1 . \text { Very bad }}$ & 31 & 1. Do not suffer & 883 & 1. Autumn preference & 10 & $\overline{1 . \mathrm{Bad}}$ (Important) & 92 & Sunday & 376 & 1. Highly pessimist & 11 \\
\hline 2. Bad & 66 & 2. Bad & 276 & 2. Mildly suffer & 460 & & 10 & 2. $\mathrm{Bad}$ & 25 & Monday & 170 & 2. Pessimist & 115 \\
\hline 3. Normal & 610 & 3. Normal & 674 & 3. Suffer & 91 & & 15 & 3. Neither & 71 & Tuesday & 253 & 3. Neither & 721 \\
\hline 4. Good & 742 & 4. Good & 405 & 4. Strongly suffer & 31 & 4. Neither & 477 & 4. Good & 48 & Wednesday & 219 & 4. Optimist & 580 \\
\hline 5. Great & 42 & 5. Very good & 79 & Total & $\overline{1,465}$ & & 283 & 5. Good (Important) & 135 & Thursday & 181 & 5. Highly optimist & 38 \\
\hline Total & 1,465 & Total & 1,465 & & & & 329 & Total & 371 & Friday & 151 & Total & 1,465 \\
\hline & & & & & & 7. Spring preference & 341 & & & Saturday & 115 & & \\
\hline & & & & & & Total & 1,465 & & & Total & 1,465 & & \\
\hline Valid choices st & itistics & & & & & & & & & & & & \\
\hline Mean choice & 2.49 & & 2.85 & & & & 5.30 & & 2.71 & & & & 2.65 \\
\hline Median choice & 2.00 & & 3.00 & & & & 5.00 & & 3.00 & & & & 3.00 \\
\hline Std. dev. & 0.65 & & 0.86 & & & & 1.27 & & 1.60 & & & & 0.70 \\
\hline
\end{tabular}


Table 3. Effect of sentiment on return expectations

This table reports the following ordered Location-Scale probit regression results:

$$
\begin{gathered}
\text { 1. } \operatorname{MOOD}_{i}=\beta_{0}+\sum_{j} \beta_{j} \operatorname{SENT}_{j, i}+\sum_{k} \beta_{k} \operatorname{CONTROLS}_{k, i}+\delta_{z_{i}}+\varepsilon_{i}, \\
\text { 2. } E\left(R_{t+1, i}\right)=\beta_{0}+\sum_{j} \beta_{j} \operatorname{SENT}_{j, i}+\sum_{k} \beta_{k} \operatorname{CONTROLS}_{k, i}+\delta z_{i}+\varepsilon_{i}, \\
\operatorname{Var}\left(\varepsilon_{i}\right)=\left[\exp \left(\gamma_{i}\right)\right]^{2},
\end{gathered}
$$

where $\mathrm{MOOD}_{i}$ is the $i$ th individual's reported "General-feeling" variable, $E\left(R_{t+1, i}\right)$ is the $i$ th individual's next-month subjective return expectation corresponding to the Dutch AEX Index; $S E N T_{j}$ are sentiment-creating variables: Generalfeeling, Perceived-weather, Sport-result, and SAD; CONTROLS $S_{k}$ are control variables: day-of-the-week control variables, market control variables, and individuals' control variables; and $z_{i}$ is the $i$ th individual variable. Valid observations incorporate the total number of complete questionnaires $(1,465)$, less subjects who have selected a nonquantitative choice ("Don't know/no opinion/not relevant").

\section{Regression $1 \quad$ Regression 2: sentiment effects on return expectations ${ }^{\mathrm{a}}$}

1.

Mood $^{\mathrm{b}}$ effects

Sentiment-creating var
General-feeling

Perceived-weather ${ }^{\mathrm{b}}$

Sport-result ${ }^{\mathrm{b}}$

SAD in the autumn ${ }^{c}$

SAD in the winter ${ }^{c}$

SAD in the spring-summer ${ }^{\mathrm{c}}$

Day-of-the-week control variables

Sunday dummy

Monday dummy

Tuesday dummy

Wednesday dummy

Thursday dummy

Friday dummy

\section{Market control variables}

Five-day-return (AEX index)

Volatility Index (VAEX)

Individuals' control variables

Gender (1-male, 2-female)

Education (1-low)

Age

Personal income (1-low)

Pessimistic-optimistic (1-pessimistic)

Fixed effects control variables

Questionnaire-wave

The $i$ th individual

The $i$ th individual scale

Valid observations ( 3 waves)

Likelihood-Ratio $\chi^{2}$ and $p$-value

Cox and Snell $\boldsymbol{R}^{2}$
2.

\section{3.}

Asymmetry of effects

All variables

Coeff. Sig.

Bad $\quad-.03 \quad .83$

Good $\quad .17 \quad .01$

$\begin{array}{lll}\mathrm{Bad} & -.00 \quad .96\end{array}$

$\begin{array}{lll}\text { Good } & -.01 & .08\end{array}$

$\begin{array}{lll}\mathrm{Bad} & -.16 \quad .17\end{array}$

Good $\quad .12 \quad .25$

$-.05 \quad .46$

$.14 \quad .04$

$.17 \quad .02$

$-.18 \quad .15$

$.28 \quad .01$

$.12 \quad .31$

$.04 \quad .76$

$-.13 \quad .31$

$-.10 \quad .43$

$.04 \quad .13$

$-.11 \quad .00$

$\begin{array}{ll}-.05 & .51\end{array}$

$-.07 \quad .00$

$.00 \quad .10$

$.02 \quad .10$

$.00 \quad .99$

$-.51 \quad .00$
.001

$.001 \quad .56$

$-.002 \quad .00$
1156

1156

$234.2 \quad .00$

${ }^{a}$ From very low expectations (Category 1) to very high expectations (Category 6).

${ }^{\mathrm{b}}$ From very bad (Category 1 ) to very good (Category 5).

${ }^{\mathrm{c}}$ From not suffering (Category 1) to strongly suffering (Category 4). 
Table 4. Time and market analysis of the individuals' sentiment effects This table reports the following ordered Location-Scale probit regression results:

$$
\begin{gathered}
\text { 1. } E\left(R_{t+1, i}\right)=\beta_{0}+\beta_{1} I S I_{i}+\sum_{k} \beta_{k} \operatorname{CONTROLS}_{k, i}+\delta z_{i}+\varepsilon_{i}, \\
\text { 2. } E\left(\operatorname{VOL}_{t+1, i}\right)=\beta_{0}+\beta_{1} I S I_{i}+\sum_{k} \beta_{k} \operatorname{CONTROLS}_{k, i}+\delta z_{i}+\varepsilon_{i}, \\
\operatorname{Var}\left(\varepsilon_{i}\right)=\left[\exp \left(\gamma_{i}\right)\right]^{2},
\end{gathered}
$$

where $E\left(R_{t+1, i}\right)$ and $E\left(V O L_{t+1, i}\right)$ are the $i$ th individual's next-month or next-year subjective return and risk expectations, respectively, corresponding to either the Dutch AEX Index or the U.S. S\&P 500 Index; ISI is the Individual Sentiment Index, composed of the sentiment-creating variables; CONTROLS $S_{k}$ are control variables: day-of-the-week, market and individual control variables; and $z_{i}$ is the $i$ th individual variable. Valid observations incorporate the total number of complete questionnaires $(1,465)$, less subjects who have selected a non-quantitative choice ("Don't know/no opinion/not relevant").

\section{Dutch AEX expectations ${ }^{\text {a }}$}

\section{Regression 1: $\quad$ Regression 2:}

Dependent variable corresponds to next:

Individual Sentiment Index (ISI) ${ }^{\mathrm{b}}$

Day-of-the-week control variables

Sunday dummy

Monday dummy

Tuesday dummy

Wednesday dummy

Thursday dummy

Friday dummy

Market control variables

Five-day-return (AEX index)

Volatility Index (VAEX)

Individuals' control variables

Gender (1-male, 2-female)

Education (1-low)

Age

Personal income (1-low)

Pessimistic-optimistic (1-pess.)

Fixed effects control variables

Questionnaire-wave

The $i$ th individual

The $i$ th individual scale

Valid observations ( 3 waves)

Likelihood-Ratio $\chi^{2}$ and $p$-value

Cox and Snell $\boldsymbol{R}^{2}$

From very

${ }^{\mathrm{b}}$ From low sentiment to high sentiment. return expectations risk expectations

1. Month 2. Year 3. Month 4. Year 5.

\section{U.S. S\&P 500 expectations ${ }^{\mathrm{a}}$}

Regression 1: $\quad$ Regression 2:

return expectations risk expectations

10 Sig. Co. Sig. Co. Sig. Co. Sig.

$\begin{array}{llllllll}-.16 .20 & -.11 .44 & .22 .15 & -.02 .88 & -.11 .44 & -.14 .34 & .26 .10 & .21 .18\end{array}$

$\begin{array}{llllllll}.27 .02 & .19 .12 & -.03 .84 & -.23 .06 & .24 .05 & .15 .27 & -.07 .61 & -.16 .26\end{array}$

$\begin{array}{llllllll}.11 .34 & .03 .80 & -.02 .87 & -.13 .30 & .05 .68 & -.06 .69 & .20 .17 & .09 .55\end{array}$

$\begin{array}{llllllll}.04 .77 & .09 .47 & -.12 .40 & -.26 .05 & .18 .17 & .11 .46 & -.05 .73 & -.05 .75\end{array}$

$\begin{array}{llllllll}.04 .77 & .09 .47 & -.12 .40 & . .26 .05 & .18 .17 & .11 .46 & -.05 .73 & .05 .75 \\ -.11 .41 & -.08 .56 & .23 .12 & -.02 .89 & -.01 .93 & -.12 .40 & .09 .55 & .06 .72\end{array}$

$\begin{array}{llllllll}-.11 .41 & -.20 .14 & .34 .03 & .04 .76 & .13 .39 & -.11 .48 & .28 .08 & .09 .57\end{array}$

$\begin{array}{llllllll}.04 .11 & -.01 .85 & -.03 .25 & -.03 .29 & .04 .12 & -.02 .55 & -.05 .10 & -.03 .27\end{array}$

$\begin{array}{llllllll}-.11 .00 & -.13 .00 & .13 .00 & .11 .00 & -.05 .02 & -.08 .00 & .08 .00 & .06 .02\end{array}$

$\begin{array}{lllllllll}-.04 .56 & -.22 .00 & -.02 .84 & .02 .83 & -.12 .11 & -.18 .03 & -.10 .27 & -.01 .89\end{array}$

$\begin{array}{llllllll}-.07 .00 & -.02 .39 & .05 .07 & .02 .31 & -.10 .00 & -.02 .50 & .08 .00 & .04 .13\end{array}$

$\begin{array}{llllllll}.00 .16 & -.01 .00 & -.01 .01 & -.01 .00 & .00 .40 & -.01 .00 & .00 .70 & -.00 .48\end{array}$

$\begin{array}{llllllll}.02 .16 & .05 .00 & -.00 .94 & -.01 .50 & .03 .01 & .05 .00 & -.02 .15 & -.03 .05\end{array}$

$\begin{array}{llllllll}-.02 .71 & -.01 .91 & -.00 .94 & .01 .90 & -.04 .42 & -.04 .47 & .04 .40 & .08 .11\end{array}$

$\begin{array}{llllllll}-.49 .00 & -.45 .00 & .58 .00 & .36 .00 & -.24 .00 & -.32 .00 & .23 .00 & .14 .02\end{array}$

$\begin{array}{llllllll}.001 .45 & .001 .40 & .002 .04 & .001 .50 & .000 .98 & .000 .99 & .000 .93 & .000 .81\end{array}$

$\begin{array}{lllllllll}-.002 .01 & -.001 .19 & .001 .26 & -.001 .47 & -.002 .07 & -.001 .31 & -.000 .99 & .000 .92\end{array}$

$\begin{array}{llllllll}1156 & 1184 & 1158 & 1173 & 982 & 974 & 1186 & 977\end{array}$

$\begin{array}{llllllll}222.6 .00 & 178.0 .00 & 199.1 .00 & 130.0 .00 & 89.2 .00 & 88.3 .00 & 71.9 .00 & 47.1 .00\end{array}$

$\begin{array}{llllllll}.18 & .14 & .16 & .10 & .09 & .09 & .07 & .05\end{array}$

.05 
Table 5. Sentiment and future investment plans

This table reports the following ordered Location-Scale probit model regression results:

$$
\begin{aligned}
\text { 1. } E\left(B S_{-} \operatorname{PLAN}_{t+1, i}\right) & =\beta_{0}+\beta_{1} E\left(R_{t+1, i}\right)+\beta_{2} E\left(\operatorname{VOL}_{t+1, i}\right)+\delta z_{i}+\varepsilon_{i}, \\
\text { 2. } E\left(B S_{-} \operatorname{PLAN}_{t+1, i}\right)= & \beta_{0}+\beta_{1} I S I_{i}+\sum_{k} \beta_{k} \operatorname{CONTROLS}_{k, i}+\delta z_{i}+\varepsilon_{i}, \\
& \operatorname{Var}\left(\varepsilon_{i}\right)=\left[\exp \left(\gamma_{i}\right)\right]^{2},
\end{aligned}
$$

where $E\left(B S \_P L A N_{t+1, i}\right)$ is the next-month plan to buy or sell stocks; $E\left(R_{t+1, i}\right)$ and $E\left(V O L_{t+1, i}\right)$ are the ith individual's next-month or next-year subjective return and risk expectations, respectively, both corresponding to the Dutch AEX Index; ISI is the Individual Sentiment Index, composed of the sentiment-creating variables; CONTROLS ${ }_{k, i}$ are control variables; and $z_{i}$ is the $i$ th individual variable. Valid observations incorporate the total number of complete questionnaires $(1,465)$, less subjects who have selected a non-quantitative choice ("Don't know/no opinion/not relevant"). The choice "Currently I do not intend to make any stock transaction" is either included within the neutral choice ("I intend to buy as many stocks as I intend to sell stocks") in Tests $1-4$, or excluded from the regression in Test 5 .

\section{$\underline{\text { Regression 1: Plans }}{ }^{\mathrm{a}}$ on $\quad \underline{\text { Regression 2: Plans }}{ }^{\mathrm{a}}$ on sentiment \\ expectations}

1. 2

Next-month Next-year Sentiment Control for Only subjects expectations expectations previous who plan to

trading trade

Next-month return expectations ${ }^{\mathrm{b}}$

Next-month risk expectations ${ }^{b}$

Next-year return expectations ${ }^{\mathbf{b}}$

Next-year risk expectations ${ }^{\mathrm{b}}$

Individual Sentiment Index (ISI) ${ }^{\mathrm{c}}$

Recent trading control variable

Bought-sold (1-sold, 5-bought)

Day-of-the-week control variables

Sunday dummy

Monday dummy

Tuesday dummy

Wednesday dummy

Thursday dummy

Friday dummy

Market control variables

Five-day-return (AEX index)

Volatility Index (VAEX)

Individuals' control variables

Gender (1-male, 2-female)

Education (1-low)

Age

Personal income (1-low)

Pessimistic-optimistic (1-pessimistic)

Fixed effects control variables

Questionnaire-wave

The $i$ th individual

The $i$ th individual scale

Valid observations ( 3 waves)

Likelihood-Ratio $\chi^{2}$ and $p$-value

Cox and Snell $R^{2}$

${ }^{\text {a}}$ From plan to only sell stocks (Category 1) to plan to only buy stocks (Category 5 ).

\begin{tabular}{|c|c|c|c|c|c|c|c|c|c|}
\hline \multirow[t]{5}{*}{$\begin{array}{c}\text { Co. } \\
.10 \\
.05\end{array}$} & $\begin{array}{l}\frac{\text { Sig. }}{.03} \\
.42\end{array}$ & Co. & Sig. & Co. & Sig. & Co. & $\underline{\text { Sig. }}$ & Co. & $\underline{\text { Sig. }}$ \\
\hline & & .17 & .00 & & & & & & \\
\hline & & .04 & .45 & & & & & & \\
\hline & & & & .20 & .01 & .21 & .00 & .33 & .01 \\
\hline & & & & & & .37 & .00 & .32 & .00 \\
\hline .23 & .23 & .22 & .25 & .23 & .22 & .27 & .17 & .62 & .07 \\
\hline .21 & .23 & .21 & .23 & .25 & .13 & .28 & .10 & .37 & .18 \\
\hline .10 & .56 & .08 & .67 & .13 & .45 & .14 & .45 & -.01 & .97 \\
\hline .08 & .65 & .05 & .79 & .10 & .58 & .08 & .66 & .23 & .46 \\
\hline-.09 & .62 & -.10 & .59 & -.08 & .68 & -.06 & .74 & -.14 & .64 \\
\hline-.00 & .99 & .02 & .92 & .04 & .86 & .08 & .68 & .04 & .90 \\
\hline-.00 & .96 & -.00 & .98 & .00 & .91 & -.02 & .68 & .01 & .87 \\
\hline-.01 & .64 & -.01 & .87 & -.02 & .61 & -.03 & .39 & -.01 & .86 \\
\hline-.19 & .08 & -.15 & .16 & -.16 & .12 & -.20 & .06 & -.27 & .20 \\
\hline-.02 & .54 & -.03 & .42 & -.03 & .40 & -.02 & .56 & .03 & .64 \\
\hline-.01 & .02 & -.01 & .06 & -.01 & .02 & -.01 & .03 & -.01 & .05 \\
\hline .01 & .38 & .01 & .43 & .02 & .21 & .01 & .40 & .02 & .40 \\
\hline .06 & .35 & .06 & .32 & .02 & .71 & .02 & .70 & -.07 & .52 \\
\hline .03 & .67 & .05 & .53 & -.06 & .38 & -.09 & .21 & -.06 & .66 \\
\hline -003 & .02 & -.003 & .03 & -.003 & .04 & -.003 & .07 & -.006 & .02 \\
\hline .000 & .93 & .000 & .85 & .000 & .72 & .001 & .53 & -.001 & .65 \\
\hline 1075 & & 1073 & & 1156 & & 1156 & & 217 & \\
\hline 28.8 & .05 & 33.5 & .01 & 32.0 & .02 & 86.1 & .00 & 55.1 & .00 \\
\hline .03 & & .03 & & .03 & & .07 & & .22 & \\
\hline
\end{tabular}

${ }^{\mathrm{b}}$ From very low expectations (Category 1 ) to very high expectations (Category 6).

${ }^{\mathrm{c}}$ From low sentiment to high sentiment. 